\title{
ÉTICA Y ESTÉTICA EN LA NOVELA REALISTA CONTEMPORÁNEA: DE MIAU (1888) A ANIMALES DOMÉSTICOS (2003)
}

\author{
MARTA Simó \\ University of Birmingham
}

\begin{abstract}
Imagen de la vida es la Novela, y el arte de componerla estriba en reproducir los caracteres humanos, las pasiones y las debilidades, lo grande y lo pequeño, las almas y las fisonomías, todo lo espiritual y lo físico que nos constituye y nos rodea, y el lenguaje, que es la marca de raza, y las viviendas, que son el signo de familia, y la vestidura, que diseña los últimos trazos externos de la personalidad: todo esto sin olvidar que debe existir perfecto fiel de balanza entre la exactitud y la belleza de la reproducción.
\end{abstract}

Benito Pérez Galdós

\section{INTRODUCCIÓN}

A lo largo de los ciento quince años que separan la publicación de Miau, de Pérez Galdós, y la cuarta novela de Marta Sanz, Animales domésticos, varias son las tendencias y contratendencias que han modelado el panorama literario hispánico. Sin embargo, a pesar de los inevitables vaivenes estéticos y conceptuales que han culminado en el sincrético laberinto de la posmodernidad, la tradición realista ha sido, y sigue siendo, una de las líneas vertebradoras del género novelesco. Así, en una de las entrevistas concedidas con motivo de la aparición de Animales domésticos, la propia autora declara abiertamente su deuda con Miau "y la literatura de Galdós que refleja el microcosmos de la familia" (2003b: $\mathrm{s} / \mathrm{p}$ ). El propio Galdós ya había expuesto en su prólogo a La Regenta, "muestra feliz del Naturalismo restaurado", la existencia de un realismo literario español, muy anterior a los dogmas llegados de Francia, cuya ley fundamental no era otra que "ajustar las ficciones del arte a la realidad de la naturaleza y el alma". Era este un modo de novelar en el que "las crudezas descriptivas" perdían toda repugnancia bajo la máscara del humor y que tenía ya en Quevedo uno de sus máximos exponentes (1991: 198-200).

Desde un ángulo contemporáneo, lejos de contemplar tal afirmación como un craso anacronismo, existe la convicción unánime de que el paradigma realista, por encima de cualquiera de sus orientaciones, bien sea la picaresca, la costumbrista, la social o la naturalista, por poner algunos ejemplos, es una de 
las constantes sobre las que se asienta el género de la novela, no solo en la Península, sino también más allá de sus fronteras.

En pleno furor del Nouveau Roman, Nathalie Sarraute visualiza la tradición literaria como una carrera de relevos, jamás interrumpida, en la que un realista como Dostoievski le pasa el testigo a Kafka (1956: 42). Para la autora, la novela tradicional, con numerosos partidarios a pesar de las distintas corrientes disonantes que se han apartado de ella, goza de una eterna juventud que le permite adaptarse a las estructuras mentales de las sucesivas sociedades sin necesidad de alterar radicalmente sus estructuras, algo que se explica por su sistema de convenciones, coherente, sólido e intemporal (1956: 93-94).

En fechas mucho más recientes, y proyectando una visión menos poetizada sobre este continuismo, afirma Pozuelo Yvancos que hoy "un buen número de novelistas contemporáneos escriben novelas de finales de siglo XIX, aunque con un lenguaje de mitad de siglo y con personajes y situaciones muy contemporáneas", actitud que califica como "conservadurismo literario" y que achaca fundamentalmente al hecho de concebir la creación en términos de simple conservación de público (2004: 32). Sea como sea, lo cierto es que la impronta de los grandes renovadores del género es más visible que nunca en la narrativa contemporánea, bien de manera palpable y hasta programática para algunos autores, bien como presencia sutil y subsumida en la propia originalidad para otros.

La huella de Galdós en la novela española del siglo xx cristaliza a partir de los años cuarenta y cincuenta en la obra de novelistas como José María Gironella, Carmen Laforet, Ramón J. Sender, Max Aub o Gonzalo Torrente Ballester, quienes rescataron y asimilaron los modos del realismo tradicional, particularmente los de signo galdosiano. Y aunque los años sesenta y setenta, dominados por el experimentalismo, fueron menos propicios a la relectura de los maestros realistas, el paradigma siguió vivo en autores como Juan Marsé e Isaac Montero (Basanta 2005: 896-899). Sin embargo, no será hasta los años ochenta, con la entrada de la llamada nueva narrativa y la recuperación del gusto por contar historias, cuando además de la trama se recobren para el estilo los rasgos inequívocos que permiten identificar la adscripción realista de una novela.

Aquellos fueron años de desconcierto y de grandes debates en torno al nuevo paradigma cultural que irrumpía con fuerza en el panorama patrio, años en que las nuevas promesas coexistían en el tiempo con autores ya consagrados de las generaciones de medio siglo o del 36: y si unos se declaraban amantes de la estética (Llorens 1984), otros enarbolaban la bandera de la frivolidad (Díaz 1990). Géneros como la novela negra, histórica, femenina o el relato breve alcanzaban una dignidad literaria nunca vista anteriormente y la introspección y la memoria se erigían como notas dominantes, hasta el punto de llevar al crítico Sanz Villanueva a afirmar que los escritores del momento eran "alérgicos a la realidad" (apud Martín 1987).

¿Qué ha cambiado desde entonces? ¿Y qué permanece? Si algo se mantiene constante es la máxima de reivindicar, por encima de todo, la libertad temática y formal: sigue habiendo lugar para la tradición y también para la ruptura, aunque algunas propuestas que veinte años atrás resultaban, si no innovadoras, por lo menos sorprendentes, como la autoficción o la mezcla de géneros en una 
misma obra, son ahora moneda corriente. Emergen nuevas formas narrativas, como el microrrelato, y el mercado sigue siendo el poder fáctico que dirige, en gran medida, los designios de la narrativa actual.

Un elemento nuevo, que progresivamente ha traído aires de renovación a la narrativa peninsular a lo largo de la última década, es la recuperación gradual de cierto realismo crítico como respuesta a algunos de los hechos que han conmocionado los cimientos del mundo desde los inicios del siglo xxı. Destaca Dieter Ingenschay en su inventario de las obras ambientadas en el contexto de la brutal matanza del 11-M que las reacciones literarias a la masacre han sido tardías y escasas, en contraste con la reacción estadounidense ante el 11-S (2011: 368-369). Aun así resulta esperanzadora la modesta nómina de tres novelas -Madrid Blues (2008), de Blanca Riestra, El corrector (2009), de Ricardo Menéndez Salmón, o La piedra en el corazón (2009), de Luis Mateo Díez- en un país en el que la literatura de las últimas décadas raramente se ha vinculado a cualquier tipo de debate ético.

Otra línea de reacción crítica surgida recientemente, muy vinculada a la anterior pero con un enfoque más metafísico, es la que se refiere al clima de terror que, tras los atentados de Nueva York, tanto se fomentó desde los órdenes del poder como mecanismo de control, y que constituye uno de los temas centrales de El país del miedo (2008), de Isaac Rosa, novela que abre una tercera etapa en la reflexión del autor sobre la sociedad española de hoy (Florénchie 2011: 264). Esta temática se retoma en La mano invisible (2011), donde Rosa recrea la angustia kafkiana en la que está sumida la clase trabajadora española, condenada a sobrevivir en una sociedad cada vez más alejada de la política social.

La recesión económica es también el detonante argumental y conceptual de Democracia (2012), de Pablo Gutiérrez, una cruda visión de la tragedia cotidiana de todos aquellos que empezaron a perderlo todo el día del desplome de Lehman Brothers, en septiembre de 2008. También se inspira en la crisis el díptico de Rafael Chirbes que traza la curva ascendente del "milagro" económico español y el descenso a la miseria de nuestros días, pues si Crematorio (2007) muestra la corrupción, el pelotazo urbanístico y la euforia del ladrillo, En la orilla (2013) escarba en las ruinas de lo que fue aquella gran falacia.

En todas estas obras se recupera para el género el espíritu que impulsó a los narradores de la segunda mitad del XIx, pintores de las costumbres de una época en que "la novela representa y analiza una historia en curso, porque la novela realista es un modo de conocer los mecanismos sociales y el funcionamiento del mundo contemporáneo" (Sotelo 2011: 669). Cierto es que uno de los temas fundamentales de la novela de las tres últimas décadas es el desencanto, lo cual desmiente esa "alergia a la realidad" que parecía aquejar a los autores españoles de los años ochenta. Sin embargo, salvando algunas excepciones -Juan Madrid, Andreu Martín, Francisco González Ledesma o Manuel Vázquez Montalbán, que en sus relatos policíacos han retratado de manera sincrónica la sociedad española de la Transición- desde los autores de la promoción de los cincuenta, parecía haber en la literatura peninsular cierto rechazo a novelar el momento histórico más inmediato, y solo en los últimos años se ha llegado a romper ese tabú. 
De esta forma de realismo testimonial y comprometido, orientado hacia la tarea de plasmar "la historia en curso", trata el presente estudio. Tomando como paradigma la cuarta novela de Marta Sanz, Animales domésticos, y sin perder de vista la obra que le sirvió de inspiración, Miau, se explorarán los caminos por los que se establece ese "perfecto fiel de balanza entre la exactitud y la belleza de la reproducción" que proclamaba Galdós en su discurso de entrada en la RAE (1991: 159), una consigna fundamental que sigue vertebrando la poética realista de nuestros días.

Tal equilibrio entre realidad y ficción solo puede abordarse desde una doble perspectiva, pues el compromiso ético que lleva a un autor a reflejar en su obra la cotidianidad de la vida y su trasfondo histórico y social no invalida la búsqueda de un estilo propio. En palabras del estudioso del XIX Yvan Lissorgues: "El arte de la novela es el resultado, nunca del todo perfecto, de una transacción entre el arte y la moral, o mejor dicho entre la estética y la ética" (2001: 56). Ambas dimensiones son indisociables y en el relato se definen recíprocamente, por lo que establecer una división tajante entre las mismas es un ejercicio artificioso y difícil. No obstante, para facilitar el análisis, la primera parte de este artículo se ocupará del sentido ético de Animales domésticos, mientras que la segunda indagará en aquellos aspectos estéticos que plantean, en esta novela de Marta Sanz, una continuidad o una ruptura respecto al referente realista en el que se inspiró.

\section{LA ÉTICA}

Resulta imposible hablar del concepto de realismo en términos absolutos, pues en cada una de sus manifestaciones intervienen variables de distinta índole: las circunstancias históricas, sociales o políticas que conforman la realidad de ese momento, los fundamentos filosóficos e ideológicos que subyacen en el discurso o el sesgo individualizado que se imprime a cada obra. Todos esos condicionantes hacen que una forma de realismo jamás pueda ser idéntica a otra.

Ni siquiera en una misma época, ni en la trayectoria de un autor, se mantienen incólumes las ideologías y los marcos teóricos: el positivismo cientificista que favoreció el tránsito de la sensibilidad romántica al naturalismo fue cediendo terreno a la problemática del yo; la pretendida impersonalidad del autor acabó revelándose como una entelequia y, en la Península, la novelística de Galdós, Pardo Bazán o Clarín dejó constancia de que la materia y el espíritu son entidades indisociables. Por todo ello sería un anacronismo tratar de establecer simetrías rígidas entre el momento realista que se vivió a finales del siglo XIx y el que se vive a principios del xxı. Ni siquiera es este equiparable al realismo social de mediados del $x x$, extremadamente objetivista, literatura revestida de cierta autoridad intelectual, y entendida, en palabras de Vázquez Montalbán, como "un elemento transformador de la conciencia y por tanto transformador de la realidad", es decir, ficción concebida como una forma de combate (1991: 17). $Y$, sin embargo, a pesar de las diferencias, es también innegable que estas tres formas de realismo comparten un sustrato común. Las tres surgen al calor de grandes conmociones históricas: la revolución burguesa de 1868, la Guerra Civil de 1936 y la subsiguiente represión de cualquier forma de libertad por parte del 
Régimen $\mathrm{y}$, ya en el siglo xxl, el espectacular y progresivo derrumbe de un país tras la crisis de 2008.

Estos tres momentos de transformación radical de las estructuras sociales y políticas han favorecido, sin lugar a dudas, la concepción de la novela como un vehículo para dar voz a los protagonistas de la historia desde el corazón de la misma, en el momento en que esta se produce; una voz colectiva que, sin embargo, no llega a anular la individualidad.

\subsection{EL DESPERTAR DE UN SENTIDO CRÍTICO}

Sería artificioso afirmar, por otra parte, que las pocas obras que en nuestros días comparten este discurso social de resistencia conforman una corriente bien establecida y homogénea, no solo por la exigüidad con que estas se publican, sino por el mismo signo de los tiempos, tan imbuido de eclecticismo y diferencia. No obstante, sí es posible constatar el surgimiento de una postura nueva ante la realidad: una disposición testimonial hacia el presente que quizá sea el inicio de una tendencia que un día llegue a capitalizar el interés que la literatura ha puesto durante los últimos años en la recuperación de la memoria histórica.

Se trata sin duda de un cambio de actitud altamente significativo que, sin embargo, todavía apunta de manera tímida, sin que estén muy claras las causas por las que la mayoría de los novelistas evitan tratar de los problemas sociales de hoy. Pablo Gutiérrez aduce rechazo al prosaísmo -"hay cierta tendencia a alejarse de lo inmediato, como si la realidad fuera algo demasiado vulgar o caduco. Aún se escriben novelas sobre la Guerra Civil como si fuera nuestro pasado más reciente" (Núñez 2012) - mientras que, para Rafael Chirbes, quien en su momento fue uno de los pioneros de la recuperación de la memoria de la barbarie con La buena letra (1992), las razones de la reticencia general a hablar de lo que ocurre hoy se encuentran en la falta de un verdadero debate intelectual, pues, si en países como Alemania el arte cobra "sentido público" y "se descifra como un mensaje ético", en España "la novela es un arte inane, una cosa como de vasito de agua y ansiolíticos en la mesilla de noche" (Azancot 2007: s/p).

En cualquier caso, el poso emocional de esta nueva actitud ante la novela es el profundo desconcierto, el desengaño, una buena dosis de nihilismo y una brutal deshumanización. Su dinámica existencial es una lucha por la supervivencia que bien podría leerse como cierto darwinismo social. El paisaje moral e intelectual que se traza es desolador, y el espíritu crítico -al sistema, a la ineptitud y corrupción de los gobernantes, a la moral colectiva, incluso- es incisivo. A pesar de todo, no hay afán adoctrinador en esta literatura: se trata de un juicio completamente alejado de cualquier maniqueísmo, una voz que solo pretende documentar lo que está pasando, sumergiéndose en las contradicciones de la realidad para tratar de entenderla, si es eso posible. Como declara Pablo Gutiérrez:

Es oportuno que haya una literatura que hable de lo que pasa, pero no con la intención de hacer una tesis ni con la de exponer un punto de vista superior al lector, porque la novela parte de la incertidumbre y de la confusión tan enorme que yo tengo. [...] Ojalá libros como este sirvan para agitar conciencias, aunque 
yo no creo en ello. La literatura social tiene lo mismo de social que de literatura. La poesía no va a cambiar el curso de las cosas. (Martín Rodrigo 2012: s/p)

\subsection{EL REINO DE LO PRIVAdO Y LA PROBLEMÁTICA DEL YO}

Si en algo es verdaderamente fiel el realismo contemporáneo al de los grandes maestros del XIX es en la concepción de la novela como el reino de lo privado, y en el convencimiento de que solo desde la individualidad es posible alcanzar una comprensión del todo. Así se expresa Rafael Chirbes al respecto: "¿De qué va lo que escribo? Del estado del alma humana a principios del siglo xxI. Si para Balzac el alma de su tiempo eran 8.000 libras de renta, echemos cuentas" (apud Rodríguez Marcos 2013a: s/p). A la radiografía de la sociedad únicamente se puede llegar a través de la intimidad de sus individuos, tanto por sus pensamientos, sus recuerdos, sus deseos y sus hechos, como por su espacio físico y su entorno humano más inmediato: de ahí la importancia que en los textos realistas adquiere la representación de la familia. Auténtico pilar de la historia social y cultural de España, reconvertida en nuestros días en el último sostén económico para muchos de los perdedores de la crisis, el núcleo familiar se perfila como el estado intermedio entre la historia personal y la historia colectiva, como una imagen a pequeña escala de lo que Galdós Ilamaba la "familia humana" (1991: 160).

Red de correspondencias fundamental en Miau, la familia constituye también el foco narrativo de Animales domésticos, así como de otras obras de Marta Sanz, es el microcosmos de muchas de las novelas de Chirbes, y está en el corazón de una de los relatos más paradigmáticamente realistas de la primera década del siglo xxI, Romanticismo (2001), de Manuel Longares. Eminentemente galdosiana en su forma y en sus temas, la novela ofrece, a partir de un nudo de relaciones familiares, el relato de lo que supuso para la burguesía y sus estamentos aledaños la muerte de Franco y la Transición a la democracia.

En esta forma de realismo que nos ocupa, la exploración existencial es tan importante como la representación de las circunstancias sociales en las que viven inmersos sus personajes y que, inevitablemente, determinan en mayor o menor medida el curso de sus vidas. Y aunque así fue también para Galdós, no es menos cierto que la problemática del yo fue para él una conquista literaria progresiva. El paso de la abstracción de sus primeras novelas, creadas a base de tipos, a un mayor grado de profundización en sus caracteres literarios, fue un proceso gradual cuyo punto de inflexión sitúa Juan Oleza en Miau (1984: 113). Y aunque la sociedad nunca dejó de ser "materia novelable", ya no parece posible explicar los actos humanos únicamente a partir de los condicionantes del medio, por lo que es en esta última novela de su "segunda etapa" cuando se lanza a explorar toda la fuerza del ser interior, que ya había empezado a prefigurarse en su obra precedente: "Galdós ha encontrado el drama del individuo, drama que se cifra en la lucha que lo escinde, en la pugna entre ser social y ser personal" (Oleza 1984: 114).

Es casi un lugar común afirmar que la novela del xIX es la historia de un individuo problemático que entra en conflicto con su medio, pero este es, en 
efecto, uno de los puntales ideológicos de la novela moderna, y Miau no constituye una excepción: Ramón Villaamil, su protagonista, el funcionario cesante que nunca llega a recibir su tan esperado nombramiento, se desvive por recuperar su estatus y volver a formar parte de la maquinaria burocrática, pero sus gestiones no dan el fruto deseado, ya que, conforme pasa el tiempo, crecen el desánimo, la impotencia y la angustia hasta que se resigna a su derrota y decide poner fin a sus días. Resulta obvia la condena directa a la cruel arbitrariedad del Estado, entendido este como poder supremo que castiga a los justos y premia a los que le roban, como Víctor Cadalso, vencedor y verdugo, como su nombre indica. Esta deshumanización del sistema, y de lo absurdo de su dinámica interna, llevaron a Ricardo Gullón a establecer un paralelismo entre Miau y El proceso, de Kafka, pues en ambas novelas el "automatismo, la impresión de aparato mecánico que produce el mundo, está sometido a una instancia remota con la cual el hombre no consigue entablar relación" (1960: 266).

Animales domésticos ofrece también un entorno hostil, un medio ambiguo y engañoso que, si en apariencia constituye un espacio de múltiples posibilidades, está plagado de obstáculos y trampas que, para ciertos personajes, se revelan como insalvables. Algunos, como Jarauta, el joven obrero que se deja la vida en un accidente laboral causado por la negligencia de sus patronos, jamás logran escapar a las limitaciones que les impone haber nacido en un estamento social poco favorecido, pese a las promesas de prosperidad y progreso para todos.

Otros son expulsados de forma poco ceremoniosa de su pequeño paraíso de la clase media, como Elías, el honrado oficinista que antes de perder su trabajo sufre en sus carnes la humillación del acoso laboral. También Elías, como Villaamil, trata de recuperar su estatus y el respeto por sí mismo: también él se enzarza en un proyecto imposible intentando ser el hombre audaz y emprendedor que no es, pidiendo un crédito al banco que, por supuesto, le es denegado, y también se declara vencido antes de descender por su propio pie al infierno de la indigencia. Animales domésticos no es un pastiche, ni Elías un remedo de Ramón Villaamil, pero son evidentes los puntos de contacto entre ambos y entre las sociedades a las que pertenecen: la tragedia que precipita a Elías al abismo es la misma que desencadena el suicidio de Villaamil, pues, salvando las diferencias superficiales entre ambas, tanto la cesantía de la España de la Restauración como el paro endémico de nuestros días condenan a sus víctimas al mismo ostracismo social.

\subsection{LA LIBERTAD INDIVIDUAL}

El naturalismo en estado puro nunca llegó a triunfar en España, y una clara muestra de ello es la trágica muerte de Villaamil, que no puede explicarse únicamente por su falta de adecuación al entorno, ni por la incapacidad de comprender los designios que rigen su destino. El suicidio de Villaamil es una decisión radical que presupone una interrogación sobre el sentido de la vida. Es un acto de albedrío, la afirmación de que por encima de las variables de la herencia 
y el medio existe una voluntad interior capaz de escoger y de rebelarse. Villaamil dedica las últimas horas de su vida a deambular por la ciudad y, a medida que se aproxima su final, la angustia y la impotencia acumuladas en su interior se van transformando en una intensa sensación de libertad. "Huid de este engañoso abismo de Madrid, que os tragará y os hará infelices para toda la vida" (2006: 403), les grita, en una escena al más puro estilo quijotesco, a unos soldados a los que toma por jóvenes labriegos. Y con estas sencillas palabras resume Villaamil lo que ha sido su existencia, una trampa: prisionero de un sistema deshumanizado y destructivo, dominado por una obsesión, atrapado en un hogar sin gobierno, a manos de una mujer empeñada en vivir siempre por encima de sus posibilidades de la que por fin tiene el valor de renegar. La cercanía de su fin afina la lucidez de Villaamil y le permite redimir, en el último instante, el gran equívoco de su existencia, pues aunque "la orgullosa declaración de independencia no oculta el fracaso que ha sido su vida" (Ribbans 1977: 409), muere libre.

Tras perder su trabajo, Elías llega pronto al convencimiento de que no se quiere (2003a: 57), y aunque intenta por todos los medios recuperar la dignidad y el respeto por sí mismo, nunca lo consigue. La lucha de Elías no se libra únicamente contra un entorno hostil, sino también contra su propia debilidad, a partes iguales. Con cierto tono de parodia, reaparece en esta novela la coordenada herencia-medio, y de nuevo se afirma el valor de la libertad individual por encima de todo, un albedrío al que Elías parece haber renunciado. $\mathrm{O}$, por lo menos, así lo ve su madre:

Tal como les ha ido, Lucrecia se cuestiona si no hubiera sido mejor renunciar a las leyes de la genética. Ella siempre había estado rodeada de hembras estúpidas: su madre, sus hermanas, su hija... Elías se parece bastante a sus hermanas. Locas, zumbadas, irresponsables, pelirrojas, mujeres que habían tirado por la borda sus aptitudes y su fuerza arbitraria. (Sanz 2003a: 62)

Sea por estoicismo o por abulia, aceptación del destino o falta de voluntad, la actitud de Elías ante su fracaso no contempla la rebelión ni el autoexamen y solo cuando su madre lo enfrenta a su propia imagen, con unas palabras de inusitada dureza, es él capaz de reaccionar:

Pero ¿tú quién te has creído que eres? No puedo prestar ni regalar dinero a un individuo que no sabe quién es ni dónde está. Ni siquiera sientes angustia. Te echan de tu trabajo, tu padre se muere, tienes un sobrino que parece un elefante, tu mujer te deja y se va con tu hermano pequeño, no sabes ni siquiera cuál es tu edad, vives con tu madre y estás contento, hijo mío. Te gustas. Tienes planes. Eres un idiota. (Sanz 2003a: 182)

Cuando se agotan las opciones que pueden Ilevarlo hacia adelante, Elías pierde la fe en el futuro y toma la determinación drástica de aniquilarse desapareciendo de su núcleo familiar y del mundo en el que ha vivido hasta entonces. Invadido por un desasimiento extremo, decreta su simbólico final, que no es otro que unirse a los indigentes que sobreviven por los jardines y las aceras de Ma- 
drid. También simbólicamente, cuando deja atrás su vida, y la casa de su madre, baja también de noche por la calle Marqués de Urquijo, hasta llegar al parque del Oeste, "a los pies del anuncio del teleférico", precisamente muy cerca del lugar que escoge Ramón Villaamil para matarse. Pero la autodestrucción de Elías es de otro signo, pues lo que certifica su muerte es la pura apatía emocional. No hay redención para Elías. No hay aprendizaje del sufrimiento, solo hay conformidad con el profundo vacío existencial.

\subsection{EL TRASFONDO SOCIAL}

Sirva este paralelismo entre Miau y Animales domésticos para anotar un punto de continuidad fundamental, no solo entre ambas novelas, sino entre dos formas de entender la realidad: las acciones de los individuos, por encima de lo heredado y de las condiciones de vida, dependen en última instancia de su ser más interior. En la obra de autores como Galdós, Clarín o Pardo Bazán, así como en la de los narradores contemporáneos que nos ocupan, la representación de la realidad histórica del momento no es en modo alguno un mero inventario de costumbres y hechos, sino una dinámica que fluye desde el alma de sus protagonistas. Como afirma Manuel Longares, el autor de Romanticismo: "La novela es el reino de lo interior, de lo privado. Podemos ocuparnos de los grandes acontecimientos políticos y sociales, pero todo eso es la vida cotidiana, lo que sucede en las habitaciones. Es a través de las relaciones privadas como podemos desentrañar el significado de una época" (Jarque 2001: s/p).

Esta línea de aproximación a la realidad social pervive en Animales domésticos, La mano invisible o Crematorio, entre otras; mundos en miniatura en los que el testimonio sociológico va unido a la introspección: los personajes no son solo piezas del gran engranaje de sus sociedades, sino que están dotados de conciencia y de voluntad, de memoria y de sentimientos; algunos llegan a cuestionarse incluso el sentido de la existencia. Y para conseguir el tan deseado efecto de realidad, y recordar también al lector que los que dan forma a la historia son los que la viven, es decir, personas como él mismo, la psicología se inserta en lo cotidiano: resulta habitual en la novela realista decimonónica, y en particular en la "serie contemporánea" de Galdós, acotar las ficciones con fechas y acontecimientos de la vida real, un procedimiento que sigue muy vivo en novelas de hoy como Democracia o Romanticismo.

Lejos de ser un recurso anquilosado, esta tendencia posee un carácter eminentemente proteico y se ha ido adaptando a los marcos de referencia del público lector, por lo que no es raro encontrar en nuestros días frecuentes alusiones a la cultura popular, tanto del cine, la televisión o la radio, como de las revistas del corazón. Este es el material que articula, por ejemplo, Daniela Astor y la caja negra (2013), de Marta Sanz, retrato de la Transición e historia personal, donde se explora la relación entre la realidad y la representación de la misma reflexionando sobre la manera en que los medios de comunicación del momento contribuían a moldear los estereotipos de género.

Apenas hay referencias culturales o mención de eventos históricos en Animales domésticos, pero aparecen suficientes indicios para determinar, desde las 
primeras escenas, que los hechos narrados se corresponden cronológicamente con el momento de la publicación de la obra en 2003. Sin embargo, aun sin el anclaje de las fechas, es posible reconocer en sus páginas una España ya cuesta abajo, seriamente minada por todos los problemas estructurales que el gran crac de 2008 no hará más que intensificar. De hecho, la propia autora se refiere a Animales domésticos como "mi novela de la crisis; hace diez años la precariedad ya empezaba a estar ahí" (Rodríguez Marcos 2013b: s/p). Y así es, pues esta gran debacle ha sido el fruto de una larga gestación. Los jalones de esta historia son esos acontecimientos cotidianos, cuantificables en cifras, que a principios del presente siglo anunciaban ya el inminente final de la bonanza que había supuesto el Ilamado "milagro" español: manifestaciones en las calles contra las regulaciones de plantilla, desempleo, dinero negro, chanchullo y picaresca, ausencia de organización sindical, pensiones a la baja y, por encima de todo, una desigualdad endémica que jamás se había llegado a erradicar. Y no solo el declive económico es manifiesto en la urdimbre social de Animales domésticos, sino que uno de sus temas centrales es también la falta de convicción ideológica que, durante los primeros años del siglo xxı, se traducía en una alarmante ceguera de la ciudadanía ante un modelo político y financiero totalmente ineficaz.

\subsection{HISTORIA COLECTIVA E HISTORIA PERSONAL}

Los actores de esta trama son los siete miembros de una familia de clase media madrileña compuesta por los padres -Julio y Lucrecia-, sus tres hijos ya adultos -Esteban, Elías y Marcela-y los respectivos cónyuges de los dos últimos, Carola y Santiago; un grupo al que se añaden Jarauta y Ángel, procedentes del entorno laboral de Esteban. Este es el pequeño universo de Animales domésticos, articulado por las relaciones entre sus personajes y por las impresiones que los unos se forman de los otros. Individuo y colectividad se complementan y se definen mutuamente: del mismo modo que el entorno contribuye a modelar el ser interior del hombre, tampoco es posible explicar las pautas de comportamiento de una comunidad, o sus inquietudes, si la consideramos como un ente abstracto y homogéneo, sin particularidades ni fisuras. Por ello, en una tendencia narrativa orientada a desentrañar los mecanismos de una sociedad desde el corazón de la misma, no es casual que la forma más paradigmática de asociación humana esté constituida por el núcleo familiar. La familia es una red de relaciones básica en la que se forja el carácter social del ser humano, es decir, la capacidad de integrarse en un grupo y de compartir intereses sus miembros, por lo que, en tanto que espacio representacional, configura el perfecto microcosmos del conjunto de la sociedad. Así fue para Balzac, para Zola y para Galdós, y así es ahora para autores como Chirbes, Longares o la misma Marta Sanz, quien afirma: "Solo puedo escribir de lo que conozco, y la familia es un reflejo en pequeño del resto del mundo" (Rodríguez Marcos 2013b: s/p).

Stephen Gilman, en su análisis de la relación entre historia y novela en la obra de Galdós, destaca que sobre esta urdimbre formada por la historia colectiva y la historia personal se superpone una dimensión simbólica que añade otro 
nivel de significado al texto: algunos personajes poseen un valor representativo asignado con antelación que los convierte en alegorías de determinados aspectos históricos o sociales de la realidad representada (1976: 21). Peter Bly retoma posteriormente esta idea y en su estudio sobre las obras de la "serie contemporánea" de Galdós, a las que también denomina "novelas de imaginación histórica", ofrece la interpretación alegórica de algunos de los personajes de Miau: el permanente estado de confusión de Luisito, el nieto enfermizo y visionario de ViIlaamil, es para Bly una proyección de la desconfianza con que Galdós contempla la España de la Restauración, mientras que la trayectoria profesional de Villaamil, con su penosa alternancia de cesantías y nombramientos, según el arbitrio de los que, a su vez, se van alternando el poder, es un claro trasunto de la inestable y caótica vida política española del siglo xix (1983: 128-132).

Existe también una sutil disposición alegórica en Animales domésticos por la que varios de sus personajes son, a la vez, construcción individual y representación de una idea. En este segundo nivel de significado algunos encarnan estructuras sociales básicas, como el principio de autoridad o la organización del trabajo, mientras que otros personifican una actitud paradigmática frente a los desafíos del sistema, como el activismo político-social o, por el contrario, la sumisión. Es importante destacar, sin embargo, que esta simbología de lo colectivo no llega a borrar las características propias de cada individuo, ya que solo toma del mismo aquellos rasgos que hacen de él un ser emblemático y que, como parte de una construcción dinámica, contribuyen a crear una imagen integral del estado de la ciudadanía española de principios del siglo xxI. Se afirma, pues, el equilibrio entre identidad individual e identidad colectiva.

\subsection{El microcosmos de Animales domésticos}

Una de las funciones básicas de la estructura familiar es la jerarquía de poder que, en Animales domésticos, tiene una línea muy bien definida:

En casa de Julio siempre se ha hecho lo que Julio ha querido. Eso él lo tiene muy claro y también deberían tenerlo claro los demás [...]. Por eso, ahora, estaba tan preocupado por Elías. Lo de Lucrecia no era nuevo. Llevaban toda la vida con un permanente tira y afloja: ella queriendo mandar como si no mandara, por debajo, despacito; él haciendo como que se dejaba, aflojando la rienda para tirar del bocado justo en las situaciones en las que era imprescindible. También despacito, dejándole creer a Lucrecia que era ella quien tenía la última palabra. Pero no era verdad. [...] Era absurdo crearse falsos motivos para reñir. (Sanz 2003a: 33)

Paradójicamente, este personaje no aparece caracterizado como un tirano, sino como un ser comprensivo, justo y conciliador: constituye una figura de autoridad positiva que, más que actuar como una fuerza opresora, funciona como un principio de cohesión. Cuando él muere nadie más es capaz de ejercer esa potestad sobre el resto de la familia y el orden establecido empieza a subvertirse peligrosamente. Por ejemplo, la suficiencia con que la insignificante 
Marcela ha considerado siempre a su madre (Sanz 2003a: 55) se traduce ahora en un intento de controlar la vida de esta última, lo que provoca un distanciamiento radical, si no definitivo, entre las dos (215). A su vez, Lucrecia, asediada por su hija, que se empeña obstinadamente en imponerle pautas de conducta, y asfixiada también por la indolencia de Elías, quien ahora instalado en su casa, además de robarle el espacio, y algo de dinero, le roba la intimidad, se siente "menos libre que nunca" (159). Y Elías, quien a la muerte del padre deja de ser momentáneamente un cero a la izquierda para asumir el papel de cabeza de familia (207), acaba sucumbiendo a su propia debilidad y sufre un proceso de regresión que lo lleva de vuelta a casa de su madre y de allí a desaparecer, calle abajo, rumbo al parque del Oeste. Por su parte, Esteban, eterno inmaduro sin conciencia de serlo, asiste al desmoronamiento de su pretendida independencia y de su activismo de ficción, por lo que pierde también a Carola, pierde su dignidad y se ve obligado a "buscar algún pretexto para seguir respetándose" (221).

Más allá del nudo familiar, la historia refleja también el vínculo entre Esteban y su compañero de trabajo, Jarauta: dos caracteres afines, pero antitéticos en esencia, pues Jarauta es un obrero y Esteban es un niño bien que juega a ser obrero (10). A juzgar por su empleo de baja cualificación, Esteban parece haber renunciado a las ventajas que pueden reportarle su formación privilegiada y su estatus social, pero en realidad se resiste a ser "un pobre Jarauta" (23) y se considera mental y culturalmente superior a su amigo, pues él "es un poeta y un intelectual que saluda a Jarauta" (85). Agitador de principios obsoletos, su comprensión del sistema de clases sigue estancada en la tradicional polaridad marxista burguesía-proletariado (175) y, aunque comparte su día a día con el lumpen, no cree formar parte del mismo, su identidad burguesa se mantiene intacta y no renuncia a la "teta de vaca de sus padres" (100), el soporte económico que podría recibir si llegara a perder su empleo. Solo cuando Julio muera y Esteban comprenda que su lugar en el mundo viene definido por sus propias decisiones, y que a los hijos de la clase media ya no les quedan prerrogativas adquiridas por nacimiento, podrá asumir que "entre él y Jarauta no existen en el fondo tantas diferencias, que los dos son un par de desgraciados y que todo está perdido" (106).

Cuando Jarauta sufre el accidente laboral que acabará costándole la vida y un grupo de trabajadores deposita en Esteban la responsabilidad del liderazgo para organizar alguna forma de protesta -alzar la voz contra el abuso, cursar una denuncia contra la empresa, defender los intereses del grupo-, su impostura queda al descubierto. Bien sea por pragmatismo o por cobardía, por cinismo o por honestidad, Esteban es incapaz de llevar a la práctica su propia ficción, huye del conflicto y traiciona a sus compañeros poniéndose del lado de los patronos:

Esteban siente que este instante es falso, que ahora mismo él debería arengar a las masas, fomentar la rebelión, por fin sacar los pies del tiesto, hinchar el pecho, descubrir lo que es y lo que no es [...] lanzar un grito de guerra y de dolor porque Jarauta va a morirse y se ha dejado la piel entre la prisa y la necesidad [...]. Esteban sabe que este es el preciso instante en el que le corresponde ser héroe, el héroe destaca y construye su propio destino [...]. Esteban rebobina 
y concluye que los héroes o tienen el riñón cubierto, o por el contrario, a los héroes no les queda nada por perder. (Sanz 2003a: 161)

Cada una de las figuras de este pequeño retablo posee una dimensión simbólica que trasciende a la anécdota. A las ya mencionadas estructuras de la jerarquía del poder y la organización del trabajo, se añaden también aquellos personajes que contribuyen a ofrecer una perspectiva de la posición social de la mujer en la España de hoy. Como es bien sabido, la época de la Transición supuso la conquista de derechos fundamentales que hasta el momento habían sido vedados a las mujeres - plena capacidad jurídica, divorcio, acceso al aborto y a la anticoncepción, entrada masiva en las universidades y en el mercado laboral-; sin embargo, décadas después, se detectan aún situaciones que obligan a cuestionar el verdadero alcance de aquellos logros: la división sexual del trabajo en el hogar sigue siendo una aspiración utópica, la brecha salarial entre los géneros es todavía un hecho constatable y la conciliación de vida laboral y familiar es, con frecuencia, un obstáculo insalvable para el progreso individual. Al margen de todas estas particularidades, y de cualquier forma de lucha, pervive también una actitud que se resume en la voluntaria renuncia a los derechos adquiridos para vivir según los patrones de conducta más tradicionales. El microcosmos de Animales domésticos refleja los dos extremos de este espectro de actitudes y posibilidades en la polaridad básica que se establece entre Carola y Marcela, pues si la primera es la encarnación de la mujer fuerte e independiente, "mujer de pelo en pecho" (141), dispuesta a mantener su individualidad a cualquier precio, la segunda es el estereotipo de la sumisión y la ausencia de horizontes propios, una personalidad retrógrada cuya única ambición en la vida es la maternidad y para quien la estampa de la dicha consiste en "un hogar tranquilo guardado por una mujer que observa a su marido subir la calle que le conduce hacia el trabajo" para ocupar después la tarde "en cualquier cosa, por ejemplo, en completar crucigramas y sopas de letras" (49).

El mundo a pequeña escala de Animales domésticos, construido a partir de una multiplicidad de momentos privados, proyecta la imagen del desencanto y el desconcierto en que vive sumida la ciudadanía española de nuestros días, tanto en el plano político como en el social. La desmembración que sufre la familia, a la muerte de Julio, traza simbólicamente la pérdida de referentes de poder y la escasa confianza de los ciudadanos en las alternativas políticas que se suceden. Por otra parte, la decadencia económica y social que sufren los miembros de la segunda generación hace patente el desposeimiento de muchos de los logros con los que a partir de la Transición se había ido construyendo un Estado de bienestar que ahora se desmantela a marchas forzadas. El matrimonio de Marcela con "un obrero especializado" (52), que tanto desagradó a Lucrecia, el desclasamiento voluntario de Esteban, que irónicamente comienza como una pose y acaba siendo real, y el descenso de Elías al agujero de la indigencia son la representación del actual reajuste de las clases sociales, en particular de las clases medias, cuyo declive va inevitablemente unido al empobrecimiento general de la sociedad. 
La precariedad laboral está prácticamente normalizada a día de hoy -miles de trabajadores indefensos con largas jornadas y sueldos de miseria, sin opciones para prosperar ni derechos sindicales-, pero a menor escala era ya un hecho en la España de 2003. El panorama desolador del desempleo masivo y los contratos basura no solo queda reflejado en la dramática situación de un parado como Elías, con nulas posibilidades de reinserción en el mercado del trabajo, sino también en la dinámica intelectual que se vive en la empresa de Esteban y Jarauta. El desgraciado accidente que sufre Jarauta no solo sirve para desenmascarar el fingido compromiso social de Esteban, sino que es también revelador de una situación habitual en épocas de depresión e inseguridad económica: el final del sindicalismo combativo. En el fondo no es la renuncia al compromiso, por parte de Esteban, lo que neutraliza la protesta colectiva por la negligencia que le cuesta la vida a Jarauta, sino la falta de capacidad de organización entre los mismos trabajadores, así como la ausencia de la infraestructura adecuada para hacerlo.

La trascendencia simbólica de los personajes y de la trama para expresar una realidad profunda es un recurso habitual en la novelística de Galdós y, en este sentido, Animales domésticos sigue plenamente la estela de la obra galdosiana. Para Galdós la realidad sensible está cargada de significaciones y, como ha afirmado Francisco Ayala, "la misión del artista consiste en detectarlas y exponerlas incorporadas en su obra", de modo que la realidad representada "expresa una realidad más alta y de mayor alcance, que desde luego la trasciende" (1974: 67).

\section{ESTÉTICA}

Para los realistas y los naturalistas decimonónicos "enfrentarse a lo contemporáneo es, quizás, el punto de partida estético más importante del realismo" (Sotelo 2001: 668). Hablar de la estética en una obra realista es, por lo tanto, hablar de su sentido ético, de esa necesidad de trasladar a la novela los conflictos que marcan una determinada época histórica, $y$, aunque el sentido ético de una obra es un elemento más de la amalgama de parámetros que definen su estética, se trata sin duda de uno de los factores más determinantes (Lissorgues 2001: 55). Sin embargo, enfrentarse a lo contemporáneo supone también considerar el modo en que se representa la complejidad del tejido social, considerar cómo se capta el latido de la vida, en las calles y en las casas, pues "en la retórica del realismo no solo es fundamental la mímesis sino también la poíesis, no solo la imitación sino también la creación" (Kronik 1988: 55). Este aspecto creativo que transforma lo observado en ficción es el foco de interés de los párrafos que siguen.

\subsection{CONTINUIDAD Y RUPTURA}

Evidentemente los fundamentos conceptuales que determinan el discurso estético de principios del siglo xxı, basados en la síntesis de ruptura e integración, en la diversidad y en la contradicción, no obedecen ya al carácter programáti- 
co y unitario que configuró la estética literaria de la segunda mitad del XIX. Sin embargo, por encima de las disparidades, es posible apreciar cierta continuidad estética respecto a la tradición en aquellos autores que todavía hoy hacen de la novela una expresión de su voz crítica.

Cada época cultural posee un carácter específico y el momento presente está dominado por la libertad formal y temática, así como por una absoluta ausencia de sistematización. En nuestros días no solo coexiste el realismo con otras tendencias narrativas antitéticas, como la literatura fantástica o experimentos de difícil clasificación, sino que dentro del mismo realismo se aprecian también distintas aproximaciones.

Sin ir más lejos, algunas de las novelas mencionadas, como Romanticismo, siguen de cerca el molde tradicional del paradigma realista decimonónico, mientras que otras, como Crematorio, sin renunciar al realismo, rompen con algunos referentes formales del pasado para reformularlos de acuerdo con un criterio personal. Y esto es así porque plasmar el mundo en las páginas de una novela implica necesariamente reflexionar sobre la forma más adecuada para hacerlo: si ese entorno espacial y humano, a la vez conflictivo y en constante cambio, se contempla como una suma de sus partes, es natural que la focalización múltiple sea uno de los modos predominantes a la hora de construir el discurso, y si la intención es presentar lo que ocurre alrededor como una entidad que fluye ante nuestros ojos, tampoco sorprende que la impersonalidad narrativa sea una de las principales consignas estéticas de esta poética.

Por todo ello, y sin ánimo de establecer un catálogo de rasgos comunes o divergentes entre el modelo realista decimonónico y el actual, una breve comparación entre Animales domésticos y Miau puede ser útil para aclarar hasta qué punto prevalecen hoy las directrices fundamentales del realismo literario de la segunda mitad del XIX.

\subsection{Estructura}

Tomemos, por ejemplo, la estructura de ambas novelas. Un sector de la crítica galdosiana ha establecido que el tiempo del relato y la distribución de los acontecimientos de la trama de Miau -novela de cuarenta y cuatro capítulos sin segmentación gráfica entre los mismos- permiten determinar su esquema narrativo según una organización tripartita de planteamiento-nudo-desenlace (Díez de Revenga 2006: 54). Animales domésticos presenta una distribución similar, algo que a primera vista podría verse como una mera coincidencia si no fuera por el hecho de que esta disposición en tres partes no se infiere de la temporalidad del relato, sino que se ofrece al lector de manera explícita e inequívoca. La novela consta únicamente de tres capítulos y cada uno de ellos viene precedido de un epígrafe que indica manifiestamente cuál es la función estructural de los mismos en el conjunto de la obra. La primera sección, "Animales domésticos", constituye una introducción en toda regla, pues en ella se presentan los temas y los personajes, a la vez que se apuntan las relaciones que estos establecen entre sí. La segunda parte, "Melodrama", se abre tras una elipsis temporal y estallan en 
ella todas las tensiones personales que se habían ido fraguando en la anterior. El título del último apartado, "Un desenlace de clase media", habla por sí solo, pues, además de incluir el término "desenlace", incorpora también una de las etiquetas más comúnmente asociadas a la novela realista del XIX: "clase media".

¿Cuál es el sentido de esta puesta en escena? ¿Por qué hacer tan evidente un recurso que se podría haber dejado en las sombras? Lejos de tratarse de un mero juego lingüístico, hay en esta apropiación de la estructura de Miau, y sobre todo en el empeño en que esto no pase inadvertido para el lector, una clara voluntad de establecer un diálogo con el referente clásico y de acercarlo al paradigma estético de hoy. Es una forma de subrayar que, por encima de las inevitables discrepancias entre ambas formas de realismo, Miau y Animales domésticos no solo comparten el afán testimonial de novelar lo cotidiano, sino que ofrecen una reflexión similar sobre la naturaleza humana. Como sostiene Gonzalo Navajas al explicar la existencia de conexiones "transtemporales" entre distintas tradiciones y momentos estéticos:

Miau, una novela abrumadoramente contaminada por el contexto burocrático en que se desarrolla, puede ser recobrada hoy a partir de la vibración existencial de su protagonista, Villaamil, cuya trayectoria progresiva hacia una ruptura final con el conformismo y la mediocridad, lo acerca a la imprevisibilidad de la condición humana actual. (Navajas 2002: 65)

\subsection{DisCURSO}

Otro punto de contacto es la naturalidad del discurso. El gran proyecto de cualquier forma de realismo es siempre conseguir que esa realidad representada, y transformada en materia narrativa por el autor, se ofrezca al lector del modo más natural posible. Por ello uno de los máximos logros de la novela realista del XIX fue la renovación del lenguaje, entendido como "la forma de expresión de las actitudes, de los temas y de las estructuras desde el punto de vista de su resultado como texto escrito" (Sobejano 1988: 583). La ausencia de un léxico ampuloso, la verosimilitud de las tramas y la impersonalidad narrativa, por la que el narrador se mantiene oculto solo para fundirse con la conciencia de sus personajes a través de los monólogos o del estilo indirecto libre, son marcas distintivas del paradigma decimonónico que siguen presentes en el modelo realista de nuestros días.

Cualquiera de las novelas mencionadas en este artículo, y entre ellas Animales domésticos, construye su mundo ficcional desde el prisma de la simplicidad, tanto en lo que se refiere al uso del idioma como a la estructura de la obra. Al respecto hay que anotar, sin embargo, que no se trata de una réplica perfecta, sino que algunos aspectos del patrón referencial decimonónico son reelaborados de acuerdo con una estética contemporánea. No es infrecuente, por ejemplo, que el hilo del discurso adopte la forma de un diálogo traspuesto a la prosa, sin signos de interrogación o guiones que señalen la alternancia de turnos de palabra (Democracia, Crematorio, En la orilla), o que el estilo directo desaparezca por completo (El país del miedo, La mano invisible) o, en las conta- 
das ocasiones en que este se muestra, quede reducido a su mínima expresión (Animales domésticos) ${ }^{1}$.

Hay también una tendencia generalizada a abandonar el uso tradicional del imperfecto, a favor del presente narrativo, para intensificar la impresión de simultaneidad entre el tiempo del relato y el momento de la lectura. Pero si hay un recurso unánimemente adoptado por todos estos autores que los aleja del molde canónico es la disolución de la trama.

\subsection{DisOLUCIÓN DE LA TRAMA}

En una época cultural caracterizada por la revalorización de la narratividad puede resultar paradójica tal renuncia a la estructura episódica, más propicia al desarrollo de una historia, pero si consideramos el trasfondo metafísico de un realismo en el que la comprensión del mundo parte de la interioridad del ser, y en el que con frecuencia se presentan individuos aislados, incapaces de comunicarse con su entorno y de integrarse en él, no produce tanta extrañeza la elección de argumentos mínimos, con una temporalidad detenida, articulados por el contrapunto de los monólogos interiores, la omnisciencia y los pasajes en estilo indirecto libre. "En una novela la tensión debe estar en el lenguaje y no en la trama", sostiene Rafael Chirbes, quien, fiel a esta filosofía, compone Crematorio y En la orilla como "un almacén de voces" (Rodríguez Marcos 2013a: s/p).

Se trata, por lo tanto, de una narrativa que transcurre en el doble plano social y psicológico, algo que también caracterizó el arte de la novela cuando el naturalismo dio un giro hacia el espiritualismo, y la verdadera historia pasó a instalarse "en la conciencia de los personajes" (Sotelo 2001: 679). Se trata, en síntesis, de obras en las que coexisten observación social y psicología ética, como recogen de nuevo estas palabras del propio Chirbes: "Estilicé el espacio, la geografía, detuve el tiempo, vacié el texto de cualquier trama que no fuera la propia tensión del lenguaje. No quería hacer una novela policíaca, ni contar que hay corrupción y ladrillos por todas partes. Quería contar el estado del alma humana, la mía, la nuestra, en un mundo así" (Azancot 2007: s/p).

Una aproximación similar, aunque con mayor complejidad argumental, presenta Animales domésticos, novela que condensa la temporalidad en los tres grandes momentos que señalan sus tres capítulos, separados por elipsis, y en la que su intensa carga de subjetividad cristaliza mediante el contrapunto y el fluir de la conciencia. Las breves secuencias de focalización interior que se suceden revelan cómo los personajes se ven a sí mismos y a los demás, desgranando así uno de los temas fundamentales de la obra, el de las relaciones humanas.

Este enfoque establece, por otra parte, un fuerte vínculo temático con Miau, novela en que Galdós subraya irónicamente la doble naturaleza de muchos de sus caracteres a través de la multiplicidad de puntos de vista (Sackett 1969: 26). Es este un proceso que se produce de forma sistemática en Animales do-

\footnotetext{
${ }^{1}$ Al respecto son muy ilustrativas las conclusiones de Amélie Florenchie (2011) en su análisis de la representación de la violencia en las novelas de Isaac Rosa, donde plantea la idea de que la ausencia de diálogo es la expresión metafórica del caos y la agresividad contenidos en el relato.
} 
mésticos y que, en última instancia, revela otro de los temas centrales de ambas obras: el antagonismo entre el ser y el parecer. La obsesión desmedida de las mujeres de la familia de Villaamil por aparentar encuentra parangón en el personaje de Esteban, quien muestra hacia afuera una personalidad impostada que nada tiene que ver con su ser más esencial, una actitud comparable con el trágico empeño de Elías en convertirse en el tipo de hombre que jamás podrá ser. Además de contribuir a la configuración literaria de los personajes de Animales domésticos, este cruce de perspectivas dirige también la estructura interna de la novela. La intersección de las distintas voces narrativas sobre una misma realidad crea un universo ambivalente en el que no hay certezas absolutas y en el que la sugerencia adquiere el rango de la afirmación.

\subsection{Caracterización simbólica}

La filiación galdosiana de Animales domésticos se manifiesta ya en la carga simbólica de su título, reminiscente de la onomatopeya que da nombre a la historia de los Villaamil. Marta Sanz recoge también el sarcasmo con que Galdós deshumaniza a sus personajes mediante la caricaturización animalesca (Rodríguez 1978: 52-54), como el irónico contraste entre la apariencia de tigre de Ramón Villaamil y su fragilidad interior, que aparece citado en las páginas de Animales domésticos como el referente directo para el retrato de su homólogo contemporáneo, Elías: "la desesperación de Elías, su progresiva metamorfosis, de ser humano a gato, de gato a remedo de tigre, es más enfermiza que la del pobre don Víctor [sic] en Miau" (Sanz 2003a: 174). Elías, marido e hijo pusilánime, es "el gato de Carola" (76) y el "minino domesticado" al que Lucrecia le ha cogido manía (159). Tampoco Esteban escapa a la mordacidad de esta forma de caracterización, y antes de que él mismo pueda comprender que en realidad no es un intelectual, sino un obrero, será la metamorfosis grotesca de una mano en garra la que señale simbólicamente el inminente colapso de la personalidad ficticia que trata de imponerse a sí mismo y a los demás:

Esteban se percata de que, poco a poco, su mano derecha se está convirtiendo en una garra. Casi no sabe coger la cuchara sin sujetarla como si fuera un palo. Es el efecto de emplear la fuerza. Vuelve a mirarse en el espejo del fondo y se tranquiliza, porque su cara es la misma que cuando estudiaba en la universidad. (Sanz 2003a: 22)

Sin embargo, son los "animales domésticos" los que constituyen el gran símbolo expresivo de la novela, un enunciado con el que se connotan las relaciones de dependencia que todos los personajes tienen respecto a otros, en particular desde la mirada de Lucrecia y Carola, los temperamentos más fuertes de toda esta galería de individuos. Los "animales domésticos" son los seres débiles, cobardes, vulnerables y manipulables. Es precisamente Carola, al reflexionar sobre la decadencia humana, tanto física como mental, quien mejor sintetiza el horizonte de sentido de la expresión: 
Se percata de cómo los seres humanos pueden dejar de serlo, poco a poco, a través de una penosa transición que los va consumiendo hasta convertirlos en algo parecido a un animalito. Carola piensa que, hoy más que nunca, cada familia tiene su animal doméstico y que, cada vez, va a haber más guacamayos y hámsters y conejos de indias que solo quieran dar vueltas dentro de su rueda de plástico. (Sanz 2003a: 73-74)

Es bien sabido que una forma de caracterización muy del agrado de Galdós fue dar nombres simbólicos a algunos de sus personajes, de modo que determinados aspectos de su carácter, o su función en el relato, quedaran plasmados de un brochazo, una técnica de la que no está exenta Miau. A la ya mencionada simbología onomástica del malvado de la historia, Víctor Cadalso, vencedor y verdugo, hay que añadir, entre otros, la de su hijo Luis, personificación de la bondad y el candor, un nombre que Díez de Revenga asocia a la figura de San Luis Gonzaga, "símbolo de la juventud inocente y caritativa, que sufre por los demás y joven muere" (2006: 27).

Este recurso, que a algunos críticos les ha parecido un tanto "trivial y barato" (Ayala 1974: 68), no deja de ser un pequeño juego retórico para añadir una nota de ironía al texto, por lo que no sorprende encontrarlo también en las páginas de una novela tan cáustica hacia el género humano como Animales domésticos. Resulta significativo, por ejemplo, que el temperamento más enérgico e independiente de la historia reciba el nombre de Carola, cuya etimología remite a "la más fuerte", o que el patriarca de la familia, que es quien mantiene el estatus y la cohesión de la misma, y quien decide lo que se hace en su casa, se llame Julio, como el líder militar y dictador de la Roma republicana. También el nombre de su esposa, Lucrecia, evocación del poeta y filósofo romano, contemporáneo de Julio César, arroja una luz sobre la función de la misma en el organigrama familiar, pues si Julio es la autoridad, ella es el juicio y la razón, aunque se trate de una inteligencia subyugada que se ha dejado eclipsar por la mediocridad de su marido, como observa su hijo Elías (Sanz 2003a: 58). Tampoco es casual que el apellido de Lucrecia sea Cordero, el mismo que lleva la familia que en la segunda serie de los Episodios nacionales encarna los vicios y las virtudes de la clase media. Un nombre y unos atributos que, a su vez, proceden de una novela histórica de Fernán Caballero, Elia, o la España treinta años ha (1857), y que Galdós recuperó para su propia obra como reconocimiento público de la admiración que sentía por la autora (Dendle 1972: 103). No es descabellado, pues, ver en la reaparición contemporánea del apellido Cordero, así como en cada uno de los guiños a la ironía galdosiana presentes en Animales domésticos, otro eslabón de una cadena en el que se unen homenaje de respeto a la tradición y voluntad de continuidad con relación a la misma.

\subsection{ENUNCIADOS DESCRIPTIVOS}

Hay, en cambio, otro plano del discurso en el que sí se aprecia cierta disparidad entre la estética realista decimonónica y la contemporánea, y este es el de la configuración de los enunciados descriptivos. 
La descripción tenía un carácter subordinado a la acción para los tratadistas clásicos de los siglos XVII y XVIII, y no fue hasta la primera mitad del XIX cuando empezó a ser considerada como un elemento más retórico que ornamental. El valor metafórico que le otorgó el romanticismo se intensificó notablemente con la entrada del realismo, hasta el punto de convertirla en uno de sus recursos más poderosos para la caracterización de los personajes y la representación del mundo. La minuciosidad y longitud de las descripciones dependía enteramente de la inclinación estilística de cada autor, pero el hecho de que Flaubert fuera más selectivo que Balzac y Galdós más prolijo que Clarín no invalidaba en ningún caso su carácter fundamental de percepción construida. Focalizada en la conciencia de un personaje que miraba a su alrededor, lejos de constituir una mera reproducción fotográfica, o un segmento despersonalizado, la descripción realista era ante todo una interpretación de la realidad. Podemos estar de acuerdo con Gonzalo Navajas cuando sostiene que "nos separa de Galdós un sistema vinculado a la descripción naturalista excesiva" (2002: 65), pero solo en lo que se refiere a la proliferación de la misma, porque el valor representativo y caracterizador que esta tenía en el realismo decimonónico se ha mantenido invariable hasta nuestros días.

Apenas hay descripciones en Animales domésticos, como tampoco las hay en Crematorio o Democracia, por poner dos ejemplos más, pero el estatus retórico de los pocos pasajes descriptivos que jalonan la novela, siempre referidos a los espacios en que se mueven los personajes, es plenamente equiparable al de de la estética del XIx. También aquí se configuran como segmentos humanizados por los que se produce la intersección entre la subjetividad y el entorno. Se centran a veces en el espacio más inmediato del personaje para subrayar aspectos de su conciencia, como la desazón con que Lucrecia contempla los restos de la comida, que no es más que un eco del malestar que le provoca su propia hija (Sanz 2003a: 196), en una escena que tanto recuerda al capítulo xvı de La Regenta. Otras veces ofrecen más bien la visión absoluta de un estrato social, como la forma en que Carola proyecta su mirada sobre el barrio de Jarauta (126-127). Constituyen, en cualquier caso, el remanso necesario para el constante fluir de la conciencia de los personajes, el amarre de la subjetividad al universo físico y social de la historia. Sirva como paradigma el pasaje que abre Animales domésticos:

Naves. Uralita. Prefabricados. Carteles rotos. Marcos de ventanas de aluminio. Cables de alta tensión. Postes de la luz. Cajas de cartón vacías. Pasos de cebra. Perros muertos. Chuchos. Anaranjados, con las orejas grandes y la panza blanca. Patas arriba. Tiesos. Duros. Rígidos. Rodeados de líquidos. A punto de pudrirse al sol. Marcas de neumáticos y de grasa en la calzada. Tufo a gasolina. Estructuras de chalés en construcción. Matrículas de coches. Cristales rotos de factorías sin chimenea. Chimeneas. Bidones. Pasos a nivel de propiedades privadas. Casetas de vigilancia. Señales de tráfico. Verjas. Farolas. Guardias jurados. Cosas que ya no sirven. Ruido de motores y de aparatos de ventilación. Aire acondicionado que rezuma. Escombreras. Cacas de rata. Esprays insecticidas. Ruedas de triciclos. Líneas continuas y discontinuas. Puntas de hierro oxidadas. Latas 
aplastadas de refrescos. Envoltorios de bollería industrial. Cascotes. Amapolas, lavandas y campanillas.

-¡Viva la vida!

Esteban acaba de mirar a su alrededor. Las amapolas le han jodido profundamente. (Sanz 2003a: 9)

No pasa inadvertido el minimalismo extremo de este fragmento, tanto por la desaparición de los verbos, de modo que la frase se reduce a su estructura más irreductible, como por la ausencia de comparaciones, metáforas, anáforas o adjetivos que dejan el campo semántico prácticamente desnudo. Y aunque es la mirada de Esteban la que focaliza la descripción, tampoco hay aquí predicados que puedan matizar el componente subjetivo, pues nada se parece ni recuerda a otra cosa, sino que los objetos descritos se presentan tal como son, ensartados en un hilo narrativo como las cuentas de un rosario. Es, precisamente, esta narrativa implícita la que demarca los distintos niveles de significado y hace que esta enumeración de elementos dispares se articule como un sistema coherente a pesar de la pretendida falta de cohesión entre los mismos. Por una parte, el catálogo de detritos, sustancias de desecho y restos orgánicos, al que se añaden las referencias a ruidos y olores desagradables, constituye todo un compendio de la vulgaridad y la decadencia que puede encerrar un mundo, en concreto el de los obreros como Esteban y Jarauta. Pero hay también un subtexto, delimitado por los pasos a nivel de las propiedades privadas, las casetas de vigilancia o los guardias jurados, que conforma un espacio de exclusión y que introduce ya la idea del choque y la asimilación de las clases, uno de los temas centrales de la novela. Y para cerrar el fragmento, en medio de toda esta degradación ambiental y de las connotaciones de hostilidad social, se pone una nota de vida y de belleza, con las amapolas, lavandas y campanillas, que para Esteban es más bien una nota de sarcasmo. En última instancia es la mirada del personaje la que confiere el verdadero contenido a la descripción.

Hay en este enclave de despojos y de marginación una visión del mundo de clara inspiración zolesca, pues del mismo modo que las novelas urbanas de Zola, el autor que tan bien retrató "la servidumbre al tajo", evocan con frecuencia "la basura material y moral, la podredumbre que supura esa época del segundo imperio tan aborrecida por el escritor" (Sobejano 1988: 593), el fragmento que abre Animales domésticos, percibido y presentado como un espacio repugnante y hostil, condensa en unas líneas toda la degradación y el prosaísmo de su universo ficcional.

\section{CONCLUSIÓN}

Afirma Yvan Lissorgues que "la forma realista del arte pocas veces se aparta de una finalidad ética" (2001: 56). Y así es. Además de ocuparse de la moral subjetiva, la mirada realista de los últimos años se ha vuelto con frecuencia hacia aquellos momentos del pasado que han definido la identidad colectiva peninsular, como la Guerra Civil o los años de la Transición. Recientemente, la novela ha plasmado también la desazón y el miedo que supone vivir en un mundo 
sometido a constante violencia y sobre el que pesa también la amenaza de la aniquilación, algo de lo que dan fe obras como La senda del drago (2006), de José Luis Sampedro, Derrumbe (2006), de Ricardo Menéndez Salmón, o la ya citada El país del miedo, de Isaac Rosa, entre otras. Sin embargo, más allá del encomiable esfuerzo por la recuperación de la memoria histórica, o de la no menos valiosa reflexión metafísica sobre el lugar del hombre en un mundo dominado por la crueldad, pocas veces a lo largo de los últimos años ha bajado la novela al nivel del suelo para ocuparse de la conflictiva realidad del momento, con sus lacras y su prosaísmo. Por ello, en una época de convulsión social y profundas transformaciones como la de ahora, es fundamental destacar la presencia de un grupo de autores para los que la escritura es una respuesta a todo lo que está sucediendo alrededor. No hay en ellos intención moralizante ni afán de reformar este entorno problemático. Tampoco hay imposiciones ideológicas. Solo hay una necesidad de ofrecer en sus ficciones un testimonio de la historia en curso, algo que recupera para la literatura contemporánea la esencia ética del realismo de la segunda mitad del siglo XIX, entregado a la tarea de comprender y representar el tejido social desde la misma naturaleza humana.

Se aprecia, entre estos autores, un inevitable cambio de perspectiva respecto a los paradigmas de la estética decimonónica: se disuelve la trama, se minimizan la anécdota, el retrato físico y la descripción, y el perspectivismo hace del mundo una entidad relativa e inestable. Sin embargo, bajo el detalle de esta aparente ruptura, y como ha reflejado la lectura comparativa de Miau y Animales domésticos, subyacen rasgos de continuidad como la dialéctica entre el sujeto y su entorno, la reflexión sobre el ser o la trascendencia simbólica de la materia: una concepción fundamental de la novela que confirma la posibilidad y la voluntad de establecer un diálogo entre esta forma contemporánea de realismo y la que renovó el género en la segunda mitad del XIX.

\section{OBRAS CITADAS}

Ayala, Francisco (1974): La novela: Galdós y Unamuno. Barcelona, Seix Barral.

Azancot, Nuria (2007): "Rafael Chirbes: "Crematorio me ha llenado de dudas y me ha tenido en un pozo oscuro durante muchos meses»". En: <http://www.elcultural.es/ articulo_imp.aspx?id=22043>. Última visita: 15.11.2013.

Basanta, Ángel (2005): "Galdós y la novela española actual". En: Actas del Octavo Congreso Internacional de Estudios Galdosianos. Las Palmas de Gran Canaria, Cabildo Insular de Gran Canaria, pp. 896-904.

Bly, Peter A. (1983): Galdós's Novel of the Historical Imagination. A Study of the Contemporary Novels. Liverpool, Francis Cairns.

Dendle, Brian (1972): "The first Cordero: Elia and the Episodios nacionales". En: Anales Galdosianos, vol. VII, pp. 103-105.

Díaz, Carolina (1990): "Eduardo Mendoza destaca que la frivolidad ya es posible en la narrativa española". En: <http://elpais.com/diario/1990/07/17/cultura/648165606_850215. html>. Última visita: 15.11.2013. 
Díez de Revenga, Francisco Javier (2006): "Introducción" a Benito Pérez Galdós: Miau. Madrid, Cátedra, pp. 11-72.

Florenchie, Amélie (2011): "Radiografía de la violencia en la sociedad española contemporánea". En: Geneviève Champeau et al. (eds.): Nuevos derroteros de la narrativa española actual. Veinte años de creación. Zaragoza, Prensas Universitarias de Zaragoza, pp. 257-274.

Gilman, Stephen (1976): "Novel and society: Doña Perfecta". En: Anales Galdosianos, vol. XI, pp. 15-27.

Gullón, Ricardo (1960): Galdós, novelista moderno. Madrid, Taurus.

Ingenschay, Dieter (2011): "Las sombras de Atocha. El 11-M en la literatura española actual". En: Geneviève Champeau et al. (eds.): Nuevos derroteros de la narrativa española actual. Veinte años de creación. Zaragoza, Prensas Universitarias de Zaragoza, pp. 365-384.

Jarque, Fietta (2001): "La burguesía se transforma, se adapta, pero no decae jamás". En: <http://elpais.com/diario/2001/01/19/cultura/979858804_850215.html>. Última visita: 15.11 .2013

Kronik, John W. (1988): "La retórica del realismo: Galdós y Clarín". En: Yvan Lissorgues (ed.): Realismo y naturalismo en España en la segunda mitad del siglo xIx. Barcelona, Anthropos, pp. 47-57.

Lissorgues, Yvan (2001): "Hacia una estética de la novela realista (1860-1897)". En: Paul Aubert (ed.): La novela en España (siglos XIX-Xx). Madrid, Casa de Velázquez, pp. 53-72.

Llorens, Isabel (1984): "Molina Foix declara pertenecer a una generación que ama la estética". En: <http://elpais.com/diario/1984/04/02/cultura/449704807_850215. html>. Última visita: 15.11.2013.

Martín, Carmelo (1987): "Los escritores son alérgicos a la realidad, según Sanz Villanueva". En: <http://elpais.com/diario/1987/04/04/cultura/544485606_850215.html>. Última visita: 15.11.2013.

Martín Rodrigo, Inés (2012): "La novela vuelve a la trinchera". En: <http://www.abc. es/20121101/cultura-libros/abci-pablo-gutierrez-democracia-201210301228. html>. Última visita: 15.11.2013.

Navajas, Gonzalo (2002): La narrativa española en la era global. Imagen. Comunicación. Ficción. Barcelona, EUB.

Núñez Jaime, Víctor (2012): "La literatura no se mide con un termómetro". En: <http:// cultura.elpais.com/cultura/2012/12/23/actualidad/1356297980_157439.html>. Última visita: 15.11.2013.

Oleza, Juan (1984): La novela del XIx. Del parto a la crisis de una ideología. Barcelona, Laia.

Pérez Galdós, Benito (2006): Miau [1888], edición de Francisco Javier Díez de Revenga. Madrid, Cátedra.

(1991): "La sociedad presente como materia novelable" [1897]. En: Laureano Bonet (ed.): Ensayos de crítica literaria. Barcelona, Península, pp. 157-165.

(1991) "Leopoldo Alas ('Clarín')" [1901]. En: Laureano Bonet (ed.): Ensayos de crítica literaria. Barcelona, Península, pp. 195-205. 
Pozuelo Yvancos, José María (2004): Ventanas de la ficción. Narrativa hispánica, siglos xx y xxI. Barcelona, Península.

Rodríguez, Alfredo (1978): Estudios sobre la novela de Galdós. Madrid, J. Porrúa Turranzas.

Rodríguez Marcos, Javier (2013a): "La gran novela de la crisis en España". En: <http:// cultura.elpais.com/cultura/2013/02/28/actualidad/1362067884_779080.html>. Última visita: 15.11.2013.

(2013b): "Rosa y negro". En: <http://cultura.elpais.com/cultura/2013/06/06/ actualidad/1370517976_178688.html>. Última visita: 15.11.2013.

Sackett, Theodore A. (1969): "The Meaning of Miau". En: Anales Galdosianos, vol. IV, pp. 25-38.

Sanz, Marta (2003a): Animales domésticos. Barcelona, Destino.

- (2003b): "Marta Sanz publica su última novela, Animales domésticos". En: <http:// www.elmundo.es/elmundolibro/2003/01/26/anticuario/1043435685.html>. Última visita: 15.11.2013.

Sarraute, Nathalie (1956): L'Ère du soupçon. París, Gallimard.

Sobejano, Gonzalo (1988): "El lenguaje de la novela naturalista". En: Yvan Lissorgues (ed.): Realismo y naturalismo en España en la segunda mitad del siglo XIX. Barcelona, Anthropos, pp. 583-615.

Sotelo Vázquez, Adolfo (2001): "Clarín, crítico de Galdós: la teoría de la novela realista en España". En: Actas del Séptimo Congreso Internacional de Estudios Galdosianos. Las Palmas de Gran Canaria, Cabildo Insular de Gran Canaria, pp. 668-684.

Vázquez Montalbán, Manuel (1991): "La novela española entre el posfranquismo y el posmodernismo". En: Yvan Lissorgues (ed.): La renovation du roman espagnol depuis 1975. Toulouse, Presses Universitaires du Mirail, pp. 13-25. 